\title{
Tangled ecosystem models: the temptation of siren songs and silence
}

\author{
JAVIER RUIZ $^{1}$ and SAKARI KUIKKA ${ }^{2}$ \\ ${ }^{1}$ Department of Coastal Ecology and Management, Instituto de Ciencias Marinas de Andalucia (ICMAN-CSIC), Campus \\ Universitario Rio San Pedro, 11510 Puerto Real, Cádiz. Spain. E-mail: Javier.ruiz@ icman.csic.es \\ ${ }^{2}$ FEM group, Department of Environmental Sciences, PO Box 65, 00014 University of Helsinki, Finland. \\ E-mail: sakari.kuikka@helsinki.fi
}

\begin{abstract}
SUMMARY: At a meeting on marine ecosystem modelling held in Barcelona in November 2010, a wide range of tools were introduced by their developers. An officer of the European Commission was invited to the meeting as a key client of these tools, and he severely criticized the tools presented as being useless. This criticism led to a strong reaction by the modellers and an interesting debate. In this paper we summarize part of this debate, focusing on one of the potential reasons why final users are not using these tools: the isomorphism between the ecosystem and its deterministic representation through mathematical equations is fragile and a new generation of maps is necessary to represent the intrinsic uncertainty of their dynamics through models.
\end{abstract}

Keywords: ecosystem models, Bayesian, ecosystem approach, uncertainty.

RESUMEN: Modelos DE ECOSISTEMA ENREVESADOS: LA TENTACIÓN DE LOS SILENCIOS Y CANCIONES DE LAS SIRENAS. - En noviembre de 2010 se celebró en Barcelona una reunión para el modelado de ecosistemas marinos en la que se presentaron una gran diversidad de estas herramientas. Un funcionario de la Comisión Europea fue invitado a esa reunión para ofrecer la visión de una institución que ha financiado el desarrollo de estas herramientas. Este funcionario realizó una crítica severa de los modelos que habían sido presentados en la reunión, calificándolos como faltos de utilidad. La afirmación generó una reacción intensa de los modeladores que asistían a la reunión y abrió la puerta a un interesante debate. En este artículo se sintetiza parte de ese debate mediante el análisis de posibles razones por las que los usuarios finales para los que se generan estas herramientas no las están utilizando: el isomorfismo entre el ecosistema y su representación determinista con ecuaciones matemáticas es frágil y resulta necesaria la generación de nuevas cartografías para simular mediante modelos la incertidumbre intrínseca de su dinámica.

Palabras clave: modelos de ecosistema, bayesiano, aproximación ecosistémica, incertidumbre.

\section{A CONTEXT OF WARNING LIGHTS}

The MARIFISH-ICES Joint Workshop on Integrated Ecosystem Modelling was held in Barcelona in November 2010 with the aim of building capacity to understand and manage marine ecosystems in a changing world. A good representation of ecosystem models aimed at providing an end-to-end representation of the ecosystem was shown at the workshop. Slide by slide, these presentations summarized years of intelligent thoughts by some of the brightest minds in the field of marine ecosystem research.
EwE, ERSEM, ATLANTIS, OSMOSE and SEAPODYM, among others, showed the beauty of their internal logic and their capacity to create dynamics analogous to the intricacies of ecosystem functioning. This included not only the lower but also the middle and higher levels of the ecosystem food web, where many commercial species are located. This initial part of the meeting took place in a context of mutual appreciation of the efforts of scientists in the room and of the sagacity of the designs and achievements obtained. However, the floor was offered not only to scientists. 
In a workshop structure that was (but should not be) unusual, the organizers also gave the floor to the clients of this work, those who pay for the research. The European Commission is a big actor for this role in Europe through funds provided by DG Research, including the E4 Unit in charge of fishing and aquaculture. An officer from this unit offered a more pessimistic view. In fact, his analysis was devastating. He criticized not the internal structure or the logic of the models but the fact that he could not identify who was implementing these tools for the management purposes that justified their creation. Although this final purpose was claimed in the grant proposals, no evidence of further implementation by decision-making bodies could be found years after the tools had been developed. As the officer stated, the very nature of a tool is to be implemented by those who need it; if that does not happen, no matter how beautiful it is, the tool is useless.

Though the words of the officer were consistent and based on facts, the reaction of the scientific arena was to shoot the messenger. The discussion revealed that part of the failure was coming from the end-users and their failure to incorporate innovative concepts in their decision-making process. It is also unbalanced to expect from marine ecosystem modelling more capabilities than is presently requested in other areas of research that do not deal with the complexities of living beings. Meteorology was mentioned as an instance in which massive investments are made in modelimplementation and data-gathering programs that only allow a prediction time of the order of days. Marine ecosystem models do not have these investments to better constrain their outputs. However, the debate also revealed that many (if not most) of the ad hoc models developed to manage resources under the ecosystem approach have problems in performing that function.

In the following days of the workshop an interesting set of debates cascaded from this rather shocking initial picture. Without denying its limitations, some of the workshop members advocated knitting the details of ecosystem functioning into mathematical complex structures in order to improve understanding. Without denying their heuristic value, a smaller portion of the participants was sensitive to the dangers that such designs involve for management purposes. The words of the Commission officer were seen as evidence of their inherent potential for transmitting too optimistic a view of science and its capacity to precisely predict the effects of management actions on ecosystems. Although the two positions were by no means exclusive, they were both present throughout the intense discussions of the conference.

Being witness to this exchange, the editor of Scientia Marina considered that its main points could benefit a wider audience through the publication of a short text with the opinion of each party to the debate. This text is therefore not intended as a review or criticism of any existing model or modelling methodology but as an articulated compilation of the arguments raised in the debate from the standpoint of those of us who feel the perils rather than the advantages of indefinite knitting into larger and larger models.

\section{ALL MODELS ARE WRONG, SOME ARE USEFUL}

The first question to consider is: what was wrong? Why did an officer from the European Commission with an unquestionable experience in managing fishery research programmes reach the conclusion that the tools developed so far to implement the ecosystem approach might be nice to the scientific eye but are useless to the rest of society.

Some context may help to understand this dilemma. Stock collapses during the $20^{\text {th }}$ century showed that statistics alone are not a reliable tool for providing scientific support for the management of living resources (Longhurst 2006). The first collapse of a fish stock cannot be predicted by modelling its statistical behaviour in the past. This evidence and the growing tendency to frame environmental issues within the ecosystem approach gave more room to biological oceanography and its understanding of ecosystem functioning. This is a discipline whose modelling roots do not rely only on statistics but-since the work of Gordon Riley and John Steele-also incorporate process quantification. By the end of the $20^{\text {th }}$ century, biological oceanography had culminated this course of mathematical synthesis with the success of MJR Fasham in simulating basinscale plankton dynamics with a seven-compartment model (Fasham et al. 1990). Fasham's accomplishment stimulated the logical creation and knitting of further compartments and of new models that evolved towards the functional group concept (Steffen 1996).

The complexities of the mathematical structures grew as the models used the functional group concept to resolve better the food web or to incorporate the multi-element nature of organisms. The functional group concept also became a meeting point between this bottom-up attempt of biological oceanography to simulate more levels of the food web and the top-down efforts by fishery scientists to implement the ecosystem approach with tools such as ECOPATH.

In the present state of this heuristic path, the structure of these models is able to accommodate the variables needed to apply the ecosystem approach for the management of marine resources. The models use spotless mathematics to construct the equations that simulate these variables and the interaction between them. These equations demand a large number of state variables and parameters but these are incorporated in a fashion coherent with existing knowledge of ecosystem functioning, which still needs development but is certainly not small.

Therefore, it seems that we have models able to focus the problem with a firm basis constructed over decades of scientific thought. Why then are these tools that look solid not widely used for knowledge-based decision-taking? A non-negligible part of this lack of 
transfer comes from the honest position of the model developers and the limitations that they perceive in their own tools. Projecting a wrong diagnosis or prognosis in the decision making may have societal consequences beyond those of the hypotheses that fence in scientific journals. This is a challenging arena when the dynamics of the conceptual representation created in models is perceived only as an approximation to the real ecosystem functioning. In the words of the famous modeller George EP Box: "[...] all models are approximations. Essentially, all models are wrong [...]; the practical question is how wrong do they have to be to not be useful" (Box and Draper 1987). In the context of the uselessness declaration by the Commission officer, the logical conclusion is that many of the models designed to implement the ecosystem approach for the management of exploited species are very wrong.

\section{THE FRAGILE ISOMORPHISM}

This does not mean that they violate any law of logic. Once the mathematical structures are created, the calculus that took Cassini to Saturn is also able to simulate a very rich set of (virtual) ecosystem dynamics. But this is different to accepting that these simulations are a mirror of (real) ecosystem dynamics. This capacity not only depends on correctly applying mathematics once nature has been mapped into mathematical structures. The cartographic fidelity of these structures is also critical. Modelling nature through mathematics relies on adequate suitable isomorphism between the two domains, i.e. a bidirectional preservation of properties when one structure is mapped into the other. Although total isomorphism between the two domains does not exist (Bueno et al. 2003), the relational structure of many natural systems is partially isomorphic to the mathematical structures used to represent them. This partial isomorphism has been a powerful tool in many branches of science and technology.

Unfortunately, our capacity to exactly map all elements of ecosystem functioning into mathematical structures is more limited. Causal dependencies are not as stable as in the abiotic realm; they evolve and may even change direction, as the roles of cod and sprat have shown in the Baltic Sea (Casini et al. 2009). In addition, the extraordinary diversity of interactions and organisms seldom fits into a tractable system of equations. The synthesis of ecosystem diversity into classes such as trophic levels, size spectra and functional types weakens the isomorphic correspondence because the classes and/or the interaction between them only offer a limited cartography of the ecosystem. Since the fidelity of this cartography is limited, the resulting mathematical maps are not an isomorphism with the original ecosystem and the bidirectional preservation of properties does not necessarily hold. Since the bidirectional preservation may not hold, then the dynamics in the mathematical domain may not be a fair representation of the dynamics in the ecosystem. Under this set of conditions, caution is necessary because these models may involve a large number of variables and parameters that interact under the high non-linearity intrinsic to ecosystems. This is a risky cocktail that can generate exuberant, though mathematically correct, dynamics that should be considered carefully before it is projected on a decision-making process.

It is not mainly a problem of numerical methods or computing power. The weak link is not the logical operation of maps once they exist but the cartographic method, which attempts to project the dynamics of ecosystems on mathematical structures inspired by the mechanical universe of Newton. When the isomorphism assumption is not strongly violated, the approach still holds. Egg dispersion or ocean biogeochemistry are strongly dependent on a physico-chemical realm whose isomorphic representation by deterministic equations is tolerable. These models have been useful tools for understanding the ocean processes that they represent. However, mechanical determinism offers a bad map of the uncertainty that characterizes many features of the ecosystems, particularly in the upper levels of the food web. It is futile to keep hammering with brute (mathematical and computational) force because the deterministic hammer is the wrong tool for capturing the inherent uncertainties and describing them honestly to the end users of the information.

\section{NON-DETERMINISTIC CARTOGRAPHIES}

RH Peters envisaged this dead end of pure deterministic constructions in his Critique for Ecology when he emphasized the need to move from describing what is possible, as dictated only by logic, towards identifying what is probable (Peters 1991). Computing this probability does not mean returning to a pure statistical approach that cannot foresee the collapse of stocks (Longhurst 2006). Nor does it mean ignoring the information content of ecological theories. This would be as unreasonable as thinking that in the future we will have a deterministic set of equations that can precisely simulate any ecosystem feature from end to end.

There are alternatives to projecting ecosystems on a Newtonian universe in which they fit poorly. The modern implementation of the Bayesian approach is able to map on mathematical structures not only our knowledge but also our uncertainties about ecological processes. In so doing, they do not produce point but probabilistic estimates to compute uncertainty and risk that are crucial to decision making (Ludwig et al. 1993). They offer us a consistent framework for describing the uncertainties of our diagnoses and prognoses given the available data and hypotheses, a strategy considered as superior both for modelling nature (Lynch et al. 2009) and for representing the uncertainties associated with this modelling (Punt and Hilborn 1997). These techniques can also consistently compute not only parametric but also structural uncertainty by analysing together several alternative theories (causal 
structures) for describing natural phenomena (Hoeting et al. 1999). This is a major advantage for modelling mid- and high trophic levels where data can be used to learn about the several hypotheses that the scientific literature proposes for describing their dynamics. Other advantages include the capacity of the Bayesian approach to consistently operate the propagation of uncertainties in cause and effect connections throughout the serial linking of model components. It is unreasonable to model this linking without any loss of information and a sensible cartography should determine a component less with information of another if they are separated by a large number of cause and effect connections. The implementation of this principle through Bayesian belief networks shows the real limitations of constraint predictions when cause and effect links are articulated in complex models, even when the best available knowledge is incorporated (Jensen 2001).

Bayesian tools are just one example of the understanding gained by implementing more sensible cartographies that incorporate the uncertainty and randomness inherent to ecosystem functioning. Other new and creative approaches have also shown our capacity to reproduce biodiversity features by incorporating the intrinsic randomness of life into circulation models (Follows et al. 2007). These models exemplify potential alternatives that open new routes for exploring our capacity to simulate ecosystem functioning through a new generation of mathematical maps.

Innovative mapping is necessary and computing uncertainty is obligatory in order to avoid future accusations that models are useless, in particular if they are claimed to be targeted towards decision making. We must avoid falling, as in Barcelona, into a Homerian and Kafkaesque trap at the same time: being enhanced by the siren song of a mechanical-universe view of the ecosystem that looks like it is doing the job and then reacting with distant silence when our clients tell us that it is not.

\section{ACKNOWLEDGEMENTS}

The authors thank the consortium of the European Project ECOKNOWS (Ref. 244706) for inspiring ideas in connection with the topics discussed in this manuscript. We also thank ICES for organizing the very open set of debates held in Barcelona.

\section{REFERENCES}

Box G.E.P., Draper N.R. 1987. Empirical Model-Building and Response Surfaces (Wiley Series in Probability and Statistics). Wiley, $688 \mathrm{pp}$.

Bueno O., French S., Ladyman S. 2003. On representing the relationship between the mathematical and the empirical. Philos. Sci. 69: 452-473.

Casini M., Hjelm J., Molinero J-C., Lövgren J., Cardinale M., Bartolino V., Belgrano A., Kornilov, G. 2009. Trophic cascades promote threshold-like shifts in pelagic marine ecosystems. PNAS. 106: 197-202.

Fasham M.J.R., Ducklow H.W. McKelvie S.M. 1990. A nitrogenbased model of plankton dynamics in the oceanic mixed layer. J. Mar. Res. 48: 591-639.

Follows M.J., Dutkiewicz S., Grant S., Chisholm S.W. 2007. Emergent Biogeography of Microbial Communities in a Model Ocean. Science 315: 1843-1846.

Hoeting J., Madigan D., Raftery A., Volinsky C. 1999. Bayesian Model Averaging. Stat. Sci. 14: 382-401.

Jensen F.V. 2001. Bayesian Networks and Decision Graphs. Springer-Verlag, New York.

Longhurst A. 2006. The sustainability myth. Fish. Res. 81: 107-112.

Ludwig D., Hilborn R., Walters C. 1993. Uncertainty, resource exploitation, and conservation: lessons from history. Science 260: 17-36.

Lynch D.R., McGillicuddy Jr. D.J., Werner F.E. 2009. Skill assessment for coupled biological/physical models of marine systems. J. Mar. Syst. 76: 1-3.

Peters R.H. 1991. A Critique for Ecology. Cambridge University Press, Cambridge, 384 pp.

Punt A.E., Hilborn R. 1997. Fisheries stock assessment and decision analysis: the Bayesian approach. Rev. Fish Biol. Fish. 7: 35-63.

Steffen W.L. 1996. A periodic table for ecology? A chemist's view of plant functional types. J. Veget. Sci. 7: 425-430.

Guest ed.: M. Bernal.

Received January 30, 2012. Accepted February 9, 2012.

Published online February 20, 2012. 